Article abstract-Chronic atrial fibrillation (AF) as a precursor of stroke was assessed over 24 years of follow-up of the general population sample at Framingham, Massachusetts. Persons with chronic established AF, with or without rheumatic heart disease (RHD), are at greatly increased risk of stroke, and the stroke is probably due to embolism. Chronic AF in the absence of RHD is associated with more than a fivefold increase in stroke incidence, while AF with RHD has a 17-fold increase. Stroke occurrence increased as duration of AF increased, with no evidence of a particularly vulnerable period. Chronic idiopathic AF is an important precursor of cerebral embolism. Controlled trials of anticoagulants or antiarrhythmic agents in persons with chronic AF may demonstrate if strokes can be prevented in this highly susceptible group.

\title{
Epidemiologic assessment of chronic atrial fibrillation and risk of stroke: The Framingham Study
}

\author{
Philip A. Wolf, M.D, Thomas R. Dawber, M.D., M.P.H., H. Emerson Thomas, Jr., M.D., and William B. \\ Kannel, M.D., M.P.H.
}

Atrial fibrillation (AF) in rheumatic heart disease (RHD), particularly with mitral stenosis, is accepted as a factor that predisposes to systemic embolism. ${ }^{1}$ Embolism from the left atrium occurs frequently and cerebral infarction is a common cause of death among RHD patients with mitral stenosis. ${ }^{2}$ There is no such agreement about risk of cerebral embolism in persons with chronic AF without rheumatic valvular disease. Beer and Ghitman ${ }^{3}$ found only one stroke among 50 patients with $\mathrm{AF}$ due to ischemic heart disease, a rate of cerebral embolism not appreciably different than the 2 percent occurring in ischemic heart disease patients without this arrhythmia. However, others have found systemic embolism to be as common in chronic AF with coronary and hypertensive heart disease as in RHD. ${ }^{4,5}$

Since it is likely that progress will come from prevention rather than from improved medical management of completed embolic strokes, it is important to determine if chronic AF predisposes to stroke. The least distorted view of the relationship of AF to stroke can be obtained through prospective epidemiologic study of a general population which is free of the biases of selection that exist in clinical and autopsy populations. We have studied the development of stroke in a population followed prospectively since 1950 , and we have related stroke incidence to antecedent cardiac rhythm and disease.

Methods. We evaluated the development of stroke in 5184 men and women, aged 30 to 62 , and free of stroke at entry, followed for 24 years. Sampling procedure, criteria, and methods of examination have been described elsewhere. ${ }^{6,7}$ Subjects were examined every 2 years. Follow-up was good, with 81 percent taking all possible examinations and less than 5 percent of the original cohort lost to mortality follow-up.

On each of the 13 biennial examinations, the subject was routinely questioned by a physician concerning habits, medications, and illnesses during the preceding 2 years. Physical examination and laboratory studies were made, and details surrounding all interim illnesses were sought. For stroke, including transient ischemic attacks (TIAs), surveillance was maintained by daily monitoring of all admissions to the only general hospital in town. If a stroke was suspected, the patient was seen in the hospital by the study neurologist. Neurologic symptoms or signs noted by the study

From the Department of Neurology (Dr. Wolf); and the Section on Preventive Medicine of the Division of Medicine (Drs. Dawber and Thomas), Boston University School of Medicine, Boston, Massachusetts; and the Heart Disease Epidemiology Study (Dr. Kannel), National Heart and Lung Institute, Framingham, Massachusetts.

Presented in part at the twenty-eighth annual meeting of the American Academy of Neurology, April 29, 1976, Toronto, Canada.

Supported in part by Research Grant NS 09695-05 from the National Institutes of Health.

Accepted for publication September 12, 1977.

Reprint requests should be addressed to Dr. Wolf, Department of Neurology, Boston University School of Medicine, 80 East Concord Street, Boston, MÁ 02118 . 
physician at biennial examination were followed by a detailed evaluation in the neurology clinic. The circumstances surrounding all illnesses and the death of each study subject were also sought by scrutiny of all available medical information, including hospital and physician records and postmortem data. Prospectively, for all illnesses under study and upon the death of each subject, all data were reviewed by a panel of physicians to determine if minimal criteria were met for the diagnosis of the diseases under study and to determine the underlying cause of death. A neurologist has participated in reviews of suspected stroke cases for the past 17 years.

Determination that a stroke has occurred can usually be made accurately if the neurologist can review the historic details of the event with the patient and his family, and can examine the patient in the hospital within a day or two of the ictus. During the past 10 years, most subjects have been admitted to the hospital by their personal physicians when stroke or TIA was suspected. Most had lumbar puncture, brain scan, EEG, and skull radiographs. Cerebral arteriography was performed on a minority of patients with stroke, but it was usually done in those suspected of subarachnoid hemorrhage. General postmortem examinations were performed in 40 percent of 1305 decedents in the cohort, including 195 persons with stroke; complete neuropathologic examination was made in half of the autopsies. Nevertheless, it is often clinically difficult to distinguish thrombotic from embolic stroke and to correctly identify small intracerebral hemorrhages. It is not always clear whether a cerebral infarct is secondary to occlusive disease of the large arteries supplying the brain or due to lacunar infarction as a consequence of occlusion of a small penetrating vessel.

To elucidate the relationship of atrial fibrillation to risk of embolic stroke, it seemed most reasonable to compare the incidence of stroke of all types, combined, in persons with and without this arrhythmia. This approach should circumvent any lack of precision in diagnostic categorization of stroke by type, in relation to antecedent AF where embolism is almost automatically diagnosed. Incidence of stroke (all types combined), was determined in the 4969 men and women free of AF and in the two subgroups of persons with $\mathrm{AF}$ on biennial examination-those with RHD and those with idiopathic AF. The duration of AF to risk of stroke may be important and, by utilizing person-years of observation, duration of the arrhythmia can be accounted for. We excluded subjects with stroke prior to the onset of AF. Persons found to be in AF for the first time when hospitalized for stroke were excluded, as were those with known paroxysmal fibrillation. In order to provide a clear and prospective picture of the development of stroke in AF, we included only subjects who were fibrillating on biennial examination.

To adjust for the effect of age and blood pressure on stroke incidence, an expected rate was calculated in each sex for each age decade and for normal, borderline, and hypertensive subjects; this gave an observed-to-expected ratio, which corrects for age and blood pressure in each sex.

Results. After 24 years of follow-up, 345 strokes occurred; 168 in men and 177 in women (table 1). Brain infarction secondary to atherosclerotic and thrombotic disease, designated atherothrombotic brain infarction (ABI), was the most common type of stroke, occurring in 97 men and 107 women and accounting for 59 percent of all strokes. Cerebral embolus, usually with a demonstrated source of emboli, occurred in 14 percent. Stroke was due to other causes in 3 percent, and TIA only accounted for 9 percent. Intracranial hemorrhage occurred in 15 percent of the cases; subarachnoid hemorrhage in 10 percent, and intracerebral hemorrhage in 5 percent.

During 481 person-years of follow-up of

Table 1. Incidence of stroke by type-24-year followup

\begin{tabular}{|c|c|c|c|}
\hline & & & Percent of \\
\hline & Men & Women & all strokes \\
\hline Atherothrombotic brain infarction & 97 & 107 & $59 \%$ \\
\hline Cerebral embolus & 24 & 24 & $14 \%$ \\
\hline Intracerebral hemorrhage & 9 & 6 & $5 \%$ \\
\hline Subarachnoid hemorrhage & 15 & 20 & $10 \%$ \\
\hline Transient ischemic attack only & 18 & 14 & $9 \%$ \\
\hline Stroke from other causes & 5 & 6 & $3 \%$ \\
\hline Total & 168 & 177 & $100 \%$ \\
\hline
\end{tabular}


Table 2. Age-sex hypertensive status adjusted rate of stroke per 1000 person-years, based on 24-year followup

$\begin{array}{lccccc}\text { Group } & \begin{array}{c}\text { Person-years } \\ \text { observation }\end{array} & \begin{array}{c}\text { Stroke events } \\ \text { observed }\end{array} & \begin{array}{c}\text { Observed } \\ \text { rate }\end{array} & \begin{array}{c}\text { Expected } \\ \text { rate }\end{array} & \text { O/E } \\ \text { No AF or RHD } & 109,051 & 311 & 2.87 & 3.11 & 0.92 \\ \text { AF only } & 481 & 20 & 41.48 & 7.43 & 5.60^{*} \\ \text { RHD and AF } & 154 & 7 & 45.45 & 2.59 & 17.56^{*} \\ * p<0.01 & & & & & \end{array}$

idiopathic $\mathrm{AF}$, there were 20 instances of stroke, 10 in men and 10 in women (table 2). This rate of 41.48/1000 person-years was 5.6 times as frequent as that in men and women of the same age and blood pressure distribution who were free of AF. In the group with AF and RHD, the age and blood pressure-adjusted risk of stroke was increased about 18 -fold in both sexes. These differences were highly significant $(p<0.01$ ) for persons with $\mathrm{AF}$, with or without RHD. Strokes among persons with chronic persistent $\mathrm{AF}$ occurred in direct relation to duration of AF (table 3). The median duration of AF prior to stroke was 39.5 months, with a distribution of intervening time from weeks to more than 10 years. Coronary heart disease (CHD) was frequent among persons with chronic $\mathrm{AF}$, whether or not a stroke occurred (table 4). Congestive heart failure (CHF) was also strongly associated with $\mathrm{AF}$ and occurred in half of those patients with chronic AF who developed stroke, and in a similar proportion of non-stroke patients with $\mathrm{AF}$. CHF often occurred at the onset of $\mathrm{AF}$, and digitalis was administered uniformly. CHD or CHF did not seem to be the cause of these strokes, since these cardiac abnormalities were equally frequent in chronic fibrillators without stroke.

It was difficult to determine the mechanism of stroke in all cases. In persons with AF and RHD, there is ample reason to believe the stroke was due to cerebral embolus, the source of the embolus being the left atrium. Review of the clinical events suggested that most of the 20 strokes occurring in the idiopathic AF group were also due to embolism. One patient had an intracerebral hemorrhage related to anticoagulant therapy that had been given to prevent further embolization following embolectomy from the left femoral artery $3 \frac{1}{2}$ months before. The other 19 patients had the abrupt onset, often while active, of focal neurologic dysfunction, reaching its maximum in moments and often clearing completely in days. None of the 20 persons had an antecedent transient ischemic attack. Eleven of these 20 died and postmortem examination was performed in eight; the brain was examined in six of these eight necropsies. In these six, a cerebral infarct corresponded in loca-
Table 3. Duration of chronic AF prior to stroke

$\begin{array}{lc}\text { Time (months) } & \text { No. cases } \\ <1 & 1 \\ 1-6 & 3 \\ 7-12 & 1 \\ 13-24 & 3 \\ 25-48 & 3 \\ 49-72 & 3 \\ 73-96 & 3 \\ 97-186 & 3 \\ & \\ \text { from documentation of AF by ECG on biennial } \\ \text { dination. }\end{array}$

tion and age to the clinical event. Infarction was multiple in one case and associated with atrial thrombus and an old splenic infarct in another. The arteries were patent in two cases, and in one of these the infarct was hemorrhagic. The absence of RHD was confirmed in all eight autopsied cases.

Discussion. There is little doubt that patients with RHD and AF, and particularly those with mitral stenosis, are at heightened risk of arterial embolization. The infarction is frequently solely in the brain; visceral or limb arterial embolism is both infrequent and often overlooked in comparison to cerebral embolism, which accounts for about half of the emboli. The mode of exitus of these patients is frequently the initial embolism, and in 65 percent, the site is the brain. Among survivors, more than half die of further cerebral emboli, often without clinical evidence of renal, mesenteric, splenic, or limb embolism. ${ }^{1}$ Systemic arterial embolism from the heart in rheumatic valvular disease may occur soon after conversion from sinus rhythm to AF, or after spontaneous, drug, or elec- 
Table 4. The frequency of coronary heart disease or congestive heart failure among nonrheumatic atrial fibrillators, men and women

\begin{tabular}{|c|c|c|c|c|c|c|}
\hline $\begin{array}{l}\text { Age at } \\
\text { entry }\end{array}$ & $\begin{array}{l}\text { Chronic AF } \\
\text { with stroke }\end{array}$ & CHF & CHD & $\begin{array}{l}\text { Chronic AF } \\
\text { without stroke }\end{array}$ & CHF & CHD \\
\hline $30-39$ & 2 & 2 & 1 & 7 & 1 & 2 \\
\hline $40-49$ & 7 & 4 & 1 & 17 & 6 & 4 \\
\hline $50-62$ & 11 & 4 & 4 & 34 & 13 & 12 \\
\hline Totals & 20 & 10 & 6 & 58 & 20 & 18 \\
\hline
\end{tabular}

trical reversion to a sinus mechanism from $\mathrm{AF} .^{2}$ Embolism also occurs during the course of chronic $\mathrm{AF}$ in RHD, usually in patients with established AF. 4.8

Evidence is accumulating that idiopathic AF is also frequently followed by systemic arterial embolization, and that cerebral infarction, secondary to embolism from the heart, is a major factor in stroke occurrence. The evidence comes from epidemiologic, clinical, and pathologic studies. In a prospective epidemiologic study of precursors of stroke among members of a retirement community, $\mathrm{AF}$ was more frequent among stroke cases, 19.7 percent versus 3.4 percent, and about onefifth of all strokes occurred in persons with AF. ${ }^{9}$

Among persons with chronic AF, cerebral infarction may be the initial and sole manifestation of systemic embolism. ${ }^{8,10,11}$ In a clinical study of chronic sinoatrial disorder, stroke occurred six times more frequently among those with chronic AF than in matched controls. ${ }^{12}$ Embolism occurs during paroxysmal AF even in the absence of organic heart disease. ${ }^{13}$ In pathologic studies embolism is now recognized as a frequent and important mechanism in cerebral infarction. ${ }^{14,15}$ In the absence of occlusive disease of the carotid artery, infarction in the territory of the middle cerebral artery is usually due to embolism from the heart, ${ }^{16,17}$ commonly arising within the fibrillating atrium. Hinton and colleagues ${ }^{11}$ studied 333 consecutively autopsied patients who have documented AF. Embolism was nearly as common in AF without RHD (35 percent) as in those with mitral valve disease (41 percent); left atrial thrombus was present in 20 percent of nonrheumatic patients with AF. Embolic infarction was solely in the brain in 53 percent, and 90 percent of the patients were functional and ambulatory prior to the stroke. Death was directly attributed to embolism in 26 percent of the cases.

The strokes occurring in chronic fibrillators in the Framingham cohort had the clinical features of embolism in 19 of the 20 events. There was the abrupt onset of deficit with maximal involvement at onset, absence of antecedent TIAs, and rapid reversal of the neurologic signs. Pathologic sup- port for embolism as the mechanism of stroke was present in 6 of the 12 who died.

Preventive implications. Persons with chronic AF, idiopathic or rheumatic in origin, are at greatly increased risk of embolic stroke. Chronic AF is not rare in the elderly, particulary among those with other risk factors for stroke-CHF, $\mathrm{CHD}$, hypertension, and $\mathrm{LVH}$ revealed by electrocardiogram (ECG). There is sufficient evidence that AF predisposes to stroke and efforts at prevention are certainly warranted. Attempts to restore sinus rhythm or to prevent left atrial thrombus formation, including controlled trials of anticoagulants in chronic fibrillators without RHD, may reduce death and disability from embolism in this stroke-prone group.

\section{Acknowledgments}

The authors wish to acknowledge the cooperation and assistance of Dr. Theodore Colton, Miss Patricia M. McNamara, Miss Rita Nickerson, and Mr. Jeremy Pool in the data handling and analysis.

\section{References}

1. Daley R, Mattingly TW, Holt CL, et al: Systemic arterial embolism in rheumatic heart disease. Am Heart J 42:566581,1951

2. Askey JM, Berstein S: The management of rheumatic heart disease in relation to systemic arterial embolism. Prog Cardiovasc Dis 3:220-232, 1960-1961

3. Beer DT, Ghitman B: Embolization from the atria in ar teriosclerotic heart disease. JAMA 177:287-291, 1961

4. Hurst JW, Paulk EA, Proctor $\mathrm{H}$, et al: Management of patients with atrial fibrillation. Am $J$ Med 37:728-741, 1968

5. Vost A, Wolochow DA, Howell DA: Incidence of infarcts of the brain in heart disease. J Pathol Bacteriol 88:463-470, 1964

6. Kannel WB, Wolf PA, Dawber TR: An evaluation of the epidemiology of atherothrombotic brain infarction. Milbank Mem Fund Q:405-448, Fall, 1975

7. Shurtleff, D: In Kannel WB, Gordon T (Editors): The Framingham Study: An Epidemiological Investigation of Cardiovascular Disease. Section 30. Washington, D C, U.S. Government Printing Office, 1974

8. Szekely P: Systemic embolism and anticoagulant prophylaxis in rheumatic heart disease. Br Med J 1:12091212,1964

9. Friedman GD, Loveland DB, Ehrlich SP: Relationship of stroke to other cardiovascular disease. Circulation 38:533541,1968 
10. Fisher CM: Treatment of chronic atrial fibrillation. Lancet $1: 1284,1972$

11. Hinton RC, Kistler JP, Fallon JT, et al: The influence of etiology of atrial fibrillation on the incidence of systemic embolism. Am J Cardiol 40:509-513, 1977

12. Fairfax AJ, Lambert CD, Leatham A: Systemic embolism in chronic sinoatrial disorder. N Engl J Med 295:190-192, 1976

13. Weintraub G, Sprecace G: Paroxysmal atrial fibrillation and cerebral embolism with apparently normal heart. $\mathrm{N}$ Engl J Med 259:875-876, 1958

14. Fisher CM, Adams RD: Observations on brain embolism with special reference to the mechanism of hemorrhagic infarction. J Neuropathol Exp Neurol 10:92-93, 1951

15. Blackwood W, Hallpike JF, Kocen RS, et al: Atheromatous disease of the carotid arterial system and embolism from the heart in cerebral infarction: A morbid anatomical study. Brain 92:897-910, 1969

16. Jorgensen L, Torvik A: Ischemic cerebrovascular diseases in an autopsy series: I. Prevalence, location and predisposing factors in verified thrombo-embolic occlusions, and their significance in the pathogenesis of cerebral infarction. J Neurol Sci 3:490-509, 1966

17. Lhermitte F, Gautier JD, Derouesne C: Nature of occlusions of the middle cerebral artery. Neurology (Minneap) $20: 82-88,1970$ 


\section{Neurology}

Epidemiologic assessment of chronic atrial fibrillation and risk of stroke: The fiamingham Study

Philip A. Wolf, Thomas R. Dawber, H. Emerson Thomas, Jr., et al.

Neurology 1978;28;973

DOI 10.1212/WNL.28.10.973

This information is current as of October 1,1978

Updated Information \&

Services

Citations

Permissions \& Licensing

Reprints including high resolution figures, can be found at: http://n.neurology.org/content/28/10/973.full

This article has been cited by 57 HighWire-hosted articles: http://n.neurology.org/content/28/10/973.full\#\#otherarticles

Information about reproducing this article in parts (figures,tables) or in its entirety can be found online at:

http://www.neurology.org/about/about_the_journal\#permissions

Information about ordering reprints can be found online:

http://n.neurology.org/subscribers/advertise

Neurology ${ }^{\circledR}$ is the official journal of the American Academy of Neurology. Published continuously since 1951, it is now a weekly with 48 issues per year. Copyright (C) 1978 by the American Academy of Neurology. All rights reserved. Print ISSN: 0028-3878. Online ISSN: 1526-632X.

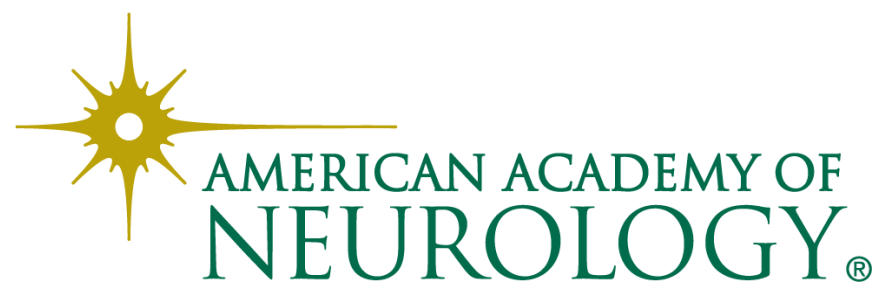

